American Journal of Pharmaceutical Education 2018; 82 (6) Article 6886.

\title{
COMMENTARY
}

\section{Adapting Leadership Styles to Reflect Generational Differences in the Academy}

\author{
Cynthia J. Boyle, PharmD, BSPharm, ${ }^{\text {a }}$ Michael Gonyeau, PharmD, MEd, BSPharm, ${ }^{\mathrm{b}}$ Schwanda K. \\ Flowers, PharmD, ${ }^{\mathrm{c}}$ Philip Hritcko, PharmD, ${ }^{\mathrm{d}}$ Reza Taheri, PharmD, MBA, ${ }^{\mathrm{e}}$ Sunil Prabhu, PhD, BPharm ${ }^{\mathrm{f}}$ \\ ${ }^{\text {a }}$ University of Maryland School of Pharmacy, Baltimore, Maryland \\ ${ }^{\mathrm{b}}$ Northeastern University, School of Pharmacy, Boston, Massachusetts \\ ${ }^{\mathrm{c}}$ University of Arkansas for Medical Sciences, College of Pharmacy, Little Rock, Arkansas \\ ${ }^{\mathrm{d}}$ University of Connecticut, School of Pharmacy, Storrs, Connecticut \\ ${ }^{\mathrm{e}}$ West Coast University, School of Pharmacy, Los Angeles, California \\ ${ }^{\mathrm{f}}$ Western University of Health Sciences, College of Pharmacy, Pomona, California \\ Submitted November 20, 2017; accepted February 6, 2018; published August 2018.
}

\begin{abstract}
The topic of adapting one's leadership style is controversial and can generate great debate. When one considers adapting one's leadership style, the question of authenticity often bubbles to the surface. This is even more compelling in the context of generational differences in our society and workforce. How can faculty members be effective if they refuse to adapt their leadership style to students' learning styles and generational characteristics? Leadership development is an ongoing focus for the American Association of Colleges of Pharmacy (AACP) to prepare faculty for roles as future leaders in higher education while a major redistribution of generations is occurring within the workforce. These generations are molded by many factors, including the economy, significant events, technology, and education. As experienced leaders, we affirm that one's leadership styles must be honed over time and adapted to reflect generational differences in academic pharmacy among colleagues, students, alumni, and stakeholders, including patients. Current and future leaders need further education and development so that their awareness of generational characteristics prepares them to adapt their leadership styles to more effectively engage and lead people of any generation.
\end{abstract}

Keywords: leadership, style, academic, pharmacy, generations

\section{BACKGROUND}

The long-forecast and biggest demographic shift in our lifetimes has arrived: the millennials have become the largest generation in the United States labor force. ${ }^{1}$ Generations represent roughly 20 year increments among the population. The Pew Research Center defines generations as the Greatest Generation (before 1928), Silent Generation (born 1928-1945), baby boomers (born 1946-1964), Gen Xers (born 1965-1980), and millennials (born 1981 to 1997). ${ }^{1}$ At any one time, roughly three generations are in the workforce, and this has implications for pharmacy faculty and graduates.

According to Carstensen's theory of socio-emotional selectivity, younger people are more likely to focus on broad and future-oriented goals, whereas older people tend to focus more on current or shorter-term goals. ${ }^{2,3}$

Corresponding Author: Cynthia J. Boyle, University of Maryland School of Pharmacy, 20 N Pine St., Baltimore, MD 21201. Tel: 410-706-5834. E-mail: cynthia.boyle@rx. umaryland.edu
Sessa and colleagues' multi-generational survey found that while all generations valued honesty, knowledge about core organizational functions, listening, and developing others, millennials valued focus and optimism more than older generations, and delegation and big picture orientation less. ${ }^{4}$ Warner and Sandberg state this differently as seasons. ${ }^{5}$ The Silent Generation or Traditionalists (winter/reap) are motivated by recognition and symbols, but boomers (autumn/harvest) appreciate recognition and status. Gen Xers (summer/till) are motivated by personal feedback and variety, while millennials (spring/sow) prefer intellectual challenges and a personal and public chance to develop. Generational dynamics are complex.

\section{Leadership Styles Must Differ to Reflect Generational Differences in Academic Pharmacy}

Leadership styles must differ to reflect generational differences in the academy. But what is the best way to rally colleagues to one's purpose, to handle problems and obstacles that inevitably arise? How do one's own ideas and experiences differ from those that one leads? According 


\section{American Journal of Pharmaceutical Education 2018; 82 (6) Article 6886.}

to George's model of authentic leadership, if we hope to be flexible and authentic leaders, we must advocate for pursuing purpose, practicing solid values, leading with heart, and demonstrating self-discipline. ${ }^{6}$ In every situation, one should always be prepared to adapt his/her leadership style based on the context of the situation and the people one is leading. It is not inauthentic to adapt leadership styles; it is smart and strategic.

So what? Why is this important to academic pharmacy? Academic pharmacy consists of several generations in significant numbers. Based on AACP institutional data, baby boomers represent $33 \%$ of the membership, Gen Xers $46 \%$, and millennials $18 \%$ and growing. People may harbor the common misconception that most faculty are baby boomers and students are millennials. Given the long educational preparation of faculty, some faculty members are stepping into their first academic appointment as millennials or even Gen Xers. Generational groups are one of many group identities that shape who we are in the world. ${ }^{5}$

Counter-arguments were established when the authors representing Cohort 5 of AACP's Academic Leadership Fellows Program (ALFP), were coached on debate skills to debate members of the 2016-2017 Cohort 13 at the 2017 Interim Meeting. ${ }^{7,8}$ The pro statement is supported in this commentary, while the con viewpoint is published in a separate article. The pro debaters anticipated arguments about inauthenticity when leadership styles are adapted. The inter-related aspects of adapting leadership styles and learning generational attributes are supported in terms of influence, strength, and change in pharmacy education.

\section{Leadership Styles}

Style relates to customs, ways of behaving, or manners of expression. Leadership styles represent a set of behaviors that one consciously chooses to use to best fit the situation. This is supported by the pivotal article Leadership That Gets Results by Daniel Goleman. ${ }^{9}$ In this article, Goleman suggests that "each style springs from different components of emotional intelligence." $\mathrm{He}$ identifies six styles ranging from coercive and authoritative to affiliative, democratic, pacesetting, and coaching. He compares these styles to golf clubs. It would be highly unusual to use only one club for a full round of golf. Instead a novice or expert golfer practices with various clubs and selects the appropriate one for a driving range, round of golf, or competitive tournament.

Taylor offers another framework by which to understand leadership styles. ${ }^{10} \mathrm{He}$ describes four styles: classic entrepreneur, modern missionary, problem solver, and solution finder. The entrepreneur is competitive and opportunistic, while the missionary looks for significance and meaning to promote impact. A problem solver focuses on concrete results and the value of experience from a top-down and take-charge approach, and the solution finder, described as modest and humble, affirms the contributions of colleagues and shared results. From these descriptions, one can understand that baby boomers who were exposed to male leaders, often with military backgrounds, might gravitate toward a problem solver style. A millennial, who experiences "multi-careerism" also known as the gig economy or "sidepreneurism" and promotes social advocacy in products and services purchased, could adopt a modern missionary leadership style or the solution finder style. ${ }^{11}$ Leadership and leadership styles can be learned so that the entrepreneurial leader can adapt to missionary or solution finder attributes in a given context.

A leadership style substantially differs from a leadership trait, which is expressed as a distinguishing characteristic such as honesty. The problem with traits is that they have little predictive value for effectiveness. However, through leadership development, individuals can expand their repertoire and can learn to flexibly deploy various leadership styles appropriate to the person, group, or situation. ${ }^{12}$ Goleman cites research which indicates that leaders with the best results do not rely on only one leadership style; they use most of them in a given week seamlessly and in different ways - depending on the business situation. ${ }^{9}$

\section{Influence}

Sarah Sladek from the American Society of Association Executives (ASAE) Center for Association Leadership offers insights on the brink of the largest shift in human capital in history. ${ }^{11}$ She states that the study of generations presents powerful clues on where to start to faster connect with and influence people of different ages. This is pertinent in higher education and in health care. Sladek suggests that in the U.S., people are holding steadfast to traditions, the concept of hierarchy, and the idea that wisdom and talent are accompanied solely by experience. Universities are known for their traditions, hierarchy, and experienced talent. This is relevant because pharmacy faculty influence people every day. Such influence starts with individual self-awareness and is amplified from a team-based, collegial approach in which the fuller complement of leadership attributes and strengths among us influences others.

\section{Strength}

The authors believe that generational differences represent a strength of our academic culture. New generations bring compelling ideas, behaviors, and viewpoints. By employing diverse leadership styles, leaders can engage 


\section{American Journal of Pharmaceutical Education 2018; 82 (6) Article 6886.}

diverse generations in the academy. This approach harnesses the power of the group and promotes development of new and exciting ideas and solutions for the challenges of today and tomorrow. Ineffective generational engagement results in divisions among colleagues and stifles creativity, growth, and advancement. ${ }^{13}$ AACP's Strategic Priority 7 states that "AACP is considered a priority organization for affiliation and leadership development by volunteers and staff." ${ }^{14}$ This requires commitment from all levels of leadership, and will require multiple leadership styles to effectively motivate constituents.

\section{Change}

By necessity, organizational leaders will have to lead differently than they have in the past. ${ }^{15}$ Data show that leaders' effectiveness has been linked to leadership style, which can have a direct impact on job satisfaction, motivation, and team performance. ${ }^{16}$ Think about how technology has fundamentally changed the way we live and work, and now think about those people who have never lived or worked without it. Have any of you reading this article read the entirety without checking your phone? Have you modified your teaching approach as the millennial generation has entered higher education? The sageon-the-stage lecturer has gone the way of the evening news anchor as a traditional source of news for the boomers. Likewise the authoritarian style of leadership is best relegated to emergency responses and military exercises. Leaders must adapt their styles to changing context to effectively lead today and in the future.

\section{CONCLUSION}

Leadership style is a set of behaviors that one consciously chooses to use to best fit the situation and person. Much like leadership styles are clubs in one's leadership golf bag, the distinctive perspectives of generations enrich schools and colleges of pharmacy and health care at large. AACP represents several generations in significant numbers, which is a great strength, but also a leadership challenge.

We must avoid limiting our views of generations to commonly portrayed caricatures. We must commit to examination and discussions of potentially divisive topics like generational workforce changes. We must also commit to investing in all generations to engage them in AACP and our institutions. Effective academic leaders will continually refine their leadership styles to lead and inspire. Their organizations will be more influential, stronger, and more adaptable to change if they leverage generational cultures and talents to meet our mission to improve health for all.

\section{ACKNOWLEDGMENTS}

We acknowledge Jonathan A. Wolfson, our capable, encouraging debate coach, and AACP's John Ressler, who facilitated our involvement in the debate. We appreciate and acknowledge our colleagues in Cohort 5 and the enthusiastic members of Cohort 13.

\section{REFERENCES}

1. Pew Research Center. The whys and hows of generations research. http://www.people-press.org/2015/09/03/the-whys-and-hows-ofgenerations-research. Accessed January 2, 2018.

2. Carstensen LL. Social and emotional patterns in adulthood: support for socioemotional selectivity theory. Psychol Aging. 1992; 7(3):331-338.

3. Hammon MM, Lester G, Clapp-Smith R, Palanski M. Age diversity and leadership: enacting and developing leadership for all ages. In: The Palgrave Handbook of Age Diversity and Work. Parry E, McCarthy J, eds. Basingstoke, UK: Palgrave Macmillan; 2017:737-759. 4. Sessa VI, Kabacoff RI, Deal J, Brown H. Generational differences in leader values and leadership behaviors. Psychologist-Manager J. 2007;10(1):47-74.

5. Generational Leadership. Ready to manage. http://blog. readytomanage.com/category/generational-leadership. Accessed January 2, 2018.

6. George B. True North: Discover Your Authentic Leadership. Hoboken, NJ: Jossey-Bass; 2007.

7. American Association of Colleges of Pharmacy. Academic Leadership Fellows Program. https://www.aacp.org/resource/ academic-leadership-fellows-program. Accessed September 10, 2017.

8. Wolfson JA. The Great Debate! A Handbook for Policy Debate and Public Forum Debate. 4th ed. Naperville, IL: LightningBolt Press; 2012.

9. Goleman D. Leadership That Gets Results. Harvard Bus Rev. 2000:78-90.

10. Taylor B. The 4 leadership styles and how to identify yours. Harvard Bus Rev. 2016: Reprint H031MR on hbr.org.

11. Sladek SL. Knowing Y: Engage the Next Generation Now. Washington, DC: ASAE: Association Management Press; 2014:49-51. 12. Northouse PG. Leadership: Theory and Practice. $5^{\text {th }}$ ed. Los Angeles, CA: Sage Publications; 2010:89,171,242.

13. White C, Conway JM, Davis PK, et al. AACP special taskforce white paper on diversifying our investment in human capital. Am J Pharm Educ. 2017;81(8):Article S13.

14. American Association of Colleges of Pharmacy. AACP Strategic Plan 2016-2019. https://www.aacp.org/sites/default/files/2017-11/ strategicplan-Sept17.pdf. Accessed September 24, 2017. 15. Anderson HJ, Baur JE, Griffith JA, Buckley MR. What works for you may not work for (gen) me: limitations of present leadership theories for the new generation. Leader Quart. 2017;28(1):245-260. 16. Judge TA, Piccolo RF. Transformational and transactional leadership: a meta-analytic test of their relative validity. $J \mathrm{Appl}$ Psychol. 2004;89(5):755-768. 